\title{
A Methyl Group Effect on the Conformation of Methylated [3.2]Metacyclophan-10-enes
}

\author{
Hans-Friedrich Grützmacher* and Ekkehard Neumann \\ Lehrstuhl I der Organischen Chemie, Fakultät für Chemie der Universität Bielefeld, \\ Postfach 100131, Universitätsstraße, W-4800 Bielefeld, Germany
}

Received December 17, 1992

Key Words: [3.2]Metacyclophan-10-enes / McMurry reaction / Reductive coupling

The syntheses of 7,13-dimethyl[3.2]metacyclophan-10-ene (5) and 7,10,11,13-tetramethyl[3.2]metacyclophan-10-ene (6) starting from 1,3-bis(4-methylphenyl)propane (1) are reported. 5 exists in the anti conformation typical of [3.2]metacyclophan- enes while 6 prefers the syn conformation because of steric repulsion between the methyl groups at the etheno bridge and at the aromatic rings.
Recently, we have reported on a convenient and efficient synthesis of [3.2]paracyclophanes by intramolecular reductive coupling of 1,3-bis(4-formylphenyl)- and 1,3-bis(4-acetylphenyl)propanes, respectively ${ }^{[1]}$, using low-valent titanium ${ }^{[2]}$. To apply this technique to the synthesis of [3.2]metacyclophanes the corresponding 1,3bis(3-acylphenyl)propanes have to be used ${ }^{[1,3]}$. The latter compounds are not directly accessible from the readily available $1,3-$ diphenylpropane by a Friedel-Crafts acylation or a related electrophilic substitution, because these reactions either preferably proceed by substitution in the para position or afford a mixture of isomers. This obstacle may be overcome by blocking the para positions of the 1,3-diphenylpropane by substituents small enough so that the steric hindrance caused by the phenylpropane unit directs the substitution into a meta position adjacent to the small substituent. In particular, one can hope for the reversible Friedel-Crafts acylation

\section{Scheme 1}
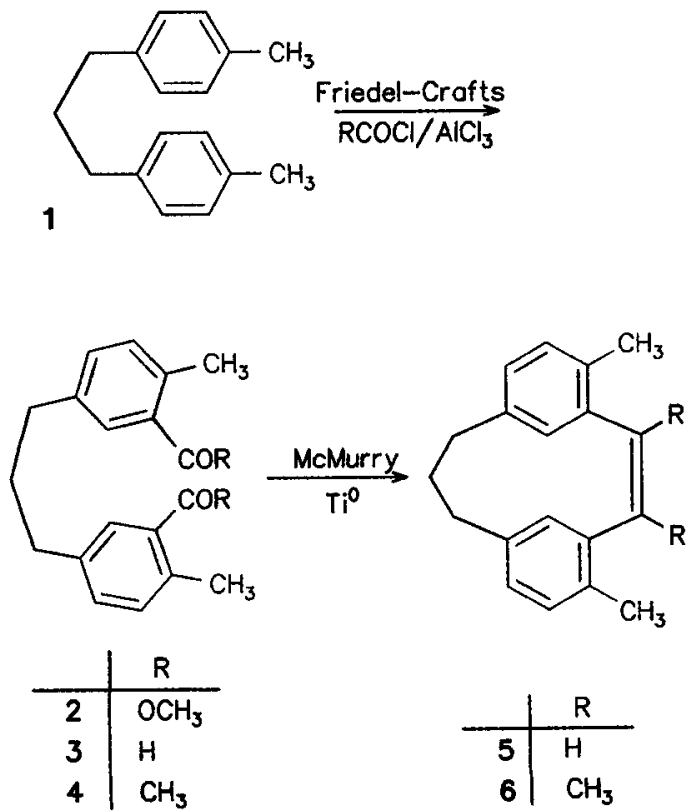

responding especially to steric effects that substitution occurs only in this position. In this paper we report on the successful syntheses of 7,13-dimethyl[3.2] metacyclophan-10-ene (5) and 7,10,11,13-tetramethyl[3.2]metacyclophan-10-ene (6) according to this route and on a remarkable effect of methyl substituents at the bridges on the conformation of these [3.2]metacyclophanes.

1,3-bis(4-methylphenyl)propane (1), prepared by hydrogenation of the condensation product of 4-methylbenzaldehyde and 4-methylacetophenone, was acetylated with oxalyl chloride $/ \mathrm{AlCl}_{3}$ and acetyl chloride $/ \mathrm{AlCl}_{3}$, respectively (Scheme 1). The Friedel-Crafts acylation of 1 with oxalyl chloride was followed by decarbonylation of the crude reaction product and esterification with methanol, giving 1,3-bis[(3-methoxycarbonyl)-4-methylphenyl]propane (2) in $58 \%$ yield after flash chromatography. The ${ }^{1} \mathrm{H}$-NMR spectrum of 2 shows a singlet at $\delta=7.72$ due to one isolated proton at the aromatic ring and singlets at $\delta=3.88$ and 2.55 for the methyl groups of the ester groups and at the aromatic rings, as expected for 2. Although a large excess of $\mathrm{AlCl}_{3}$ was used to ensure reversible reaction conditions for the acylation, the ${ }^{1} \mathrm{H}-\mathrm{NMR}$ spectrum also revealed the presence of about $20 \%$ of isomers of 2 by additional signals at $\delta=7.67(\mathrm{ar}-\mathrm{H}), 3.84\left(\mathrm{CO}_{2} \mathrm{CH}_{3}\right)$, and $2.33\left(\mathrm{ar}-\mathrm{CH}_{3}\right)$. These isomers could not be eliminated by column chromatography. Hence, the mixture of the diesters was transformed into 1,3-bis(4formyl-3-methylphenyl)propane (3) and its isomers by reduction with $\mathrm{LiAlH}_{4}$ and oxidation of the resulting diols with pyridinium chlorochromate. Again, the ${ }^{1} \mathrm{H}-\mathrm{NMR}$ spectrum of the reaction product (ca. 50\% yield) shows the presence of isomers of 3 by additional signals for the proton of the aldehyde groups. Similarly, 1,3-bis(3-acetyl-4-methylphenyl)propane (4) was obtained by reaction of 1 with acetyl chloride in the presence of a large excess of $\mathrm{AlCl}_{3}$ in $47 \%$ yield after recrystallization from ethanol. The ${ }^{1} \mathrm{H}-$ NMR spectrum exhibits the expected singlet of one isolated proton at the aromatic rings at $\delta=7.48$, and by NOE experiments it was shown that this isolated proton is located in the ortho position to the trimethylene chain as expected for 4 . However, again the presence of ca. $10 \%$ of other isomers of 4 was detected by additional signals in the ${ }^{1} \mathrm{H}$-NMR spectrum.

Since neither 3 nor 4 could by obtained free of isomers the crude material was subjected to a cyclization by the McMurray reaction using high-dilution techniques and a large excess of the low-valent 
titanium reagent in THF. After purification of the reaction products by column chromatography 7,13-dimethyi[3,2] metacyclophan-10ene (5) and 7,10,11,13-tetramethyl[3.2]metacyclophan-10-ene (6) were obtained in 18 and $26 \%$ yield, respectively, free of other isomers. Very likely the isomers of 5 and $\mathbf{6}$ with one or both acyl groups in the ortho position to the trimethylene chain do not couple to cyclophanes but polymerize under these reaction conditions.

Metacyclophanes adopt either a "stair-case" anti conformation or a syn conformation with overlaying aromatic rings ${ }^{[4]}$ (Scheme 2). Depending on the size of the bridges ${ }^{[5]}$ and on the presence of intraannular substituents ${ }^{[6]}$, the interconversion between the syn and anti conformers may occur by ring flipping. The preferred conformation and the conformational mobility of a metacyclophane is easily derived from the ${ }^{1} \mathrm{H}-\mathrm{NMR}$ spectrum ${ }^{[4]}$. While the intra-annular proton $\mathrm{H}_{\mathrm{i}}$ at the aromatic ring of the syn conformer gives rise to a singlet with a normal $\delta$ value for protons at aromatic systems, the $\mathrm{H}_{i}$ of the anti conformers is situated above the other aromatic ring, and the ring current exercises a large high-field shift of the corresponding signal in the ${ }^{1} \mathrm{H}-\mathrm{NMR}$ spectrum. The protons of the benzylic methylene groups of the bridges differ in the anti as well as in the $s y n$ conformation by their orientation relative to the aromatic rings and are expected to give rise to an $\mathrm{AB}$ spin system in the ${ }^{1} \mathrm{H}$ NMR spectrum further complicated by coupling with the protons at the neighboring $\mathrm{C}$ atoms. Thus, a complicated signal pattern is observed if the metacyclophane is a rigid molecule. In the case of a flexible metacyclophane, however, anti-anti (or syn-syn) interconversion of the conformers causes the protons in the benzylic positions to become equivalent, and the AB systems of the individual $\mathrm{CH}_{2}$ groups of the bridges collapse at least at higher temperatures by fast isomerization.

\section{Scheme 2}
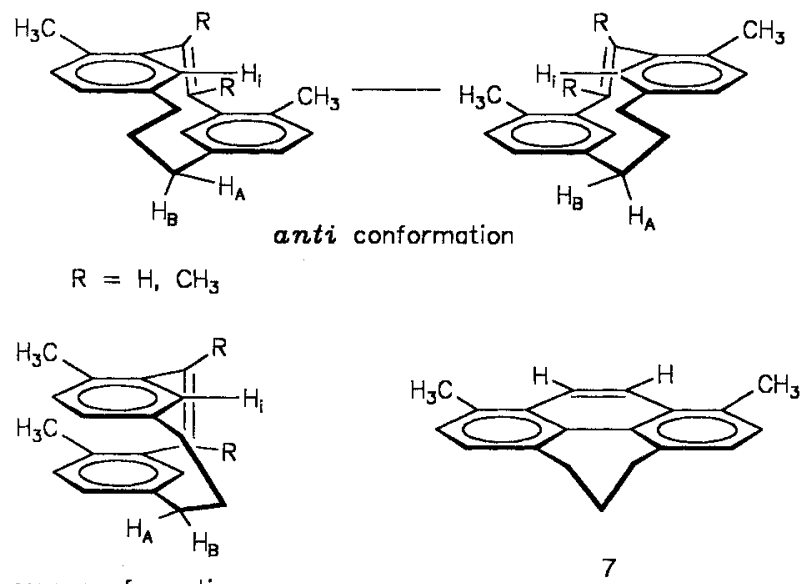

syn conformation

The singlet of $\mathrm{H}_{\mathrm{i}}$ at $\delta=6.05$ in the ${ }^{1} \mathrm{H}-\mathrm{NMR}$ spectrum of 5 shows clearly that $\mathbf{5}$ adopts a "stair-case" anti conformation as known for other [3.2] metacyclophan-10-enes ${ }^{[1,3]}$ and [3.2] metacyclophanes ${ }^{[4,5]}$. In addition, the protons of the trimethylene bridge give rise to a triplet and a quintet centered at $\delta=2.78$ and 1.81 , respectively, proving a fast interconversion of the two anti conformations of 5 by ring flipping (Scheme 2). No change of the ${ }^{1} \mathrm{H}-\mathrm{NMR}$ spectrum was observed by cooling the $\mathrm{CDCl}_{3}$ solution of 5 to $-80^{\circ} \mathrm{C}$; hence, 5 is a rather flexible molecule. On exposure to air $\mathbf{5}$ is oxidized to 1,8-dimethyl-4,5-propanophenanthrene (7) (Scheme 2) which is easily identified by characteristic singlets of the methyl groups in the ${ }^{1} \mathrm{H}$-NMR spectrum. Oxidative coupling of the two phenyl groups is quite common for unsaturated metacyclophanes in the stair-case conformation $^{[7]}$, but 5 appears to be especially sensitive to this reaction. For example, 7 is also formed during column chromatography of $\mathbf{5}$ on silica gel if the silica gel is not neutralized with $\mathrm{K}_{2} \mathrm{CO}_{3}$.

In contrast to 5 , the tetramethylated metacyclophane 6 is not easily oxidized by air and prefers a syn conformation. This is clearly seen from its ${ }^{1} \mathrm{H}-\mathrm{NMR}$ spectrum showing the singlet of the intraannular proton $\mathrm{H}_{\mathrm{i}}$ at $\delta=6.98$ apart from the $\mathrm{AB}$ spin system at 6.52 of the other two protons at the aromatic rings. The methyl substituents give rise to singlets at $\delta=1.97$ and 2.12 , and the protons of the trimethylene bridge generate a complicated signal pattern as expected for a rigid syn-[3.2] metacyclophane. The protons of the benzylic $\mathrm{CH}_{2}$ group procedure an $\mathrm{AB}$ spin system at $\delta=2.51$ and 2.87 which is further split by coupling with the protons of the central $\mathrm{CH}_{2}$ group. This central $\mathrm{CH}_{2}$ group also gives rise to an $\mathrm{AB}$ system at $\delta=1.35$ and 2.12 , the low-field part being hidden by the large signal of a methyl group. This peak pattern ascribed to six chemically distinct protons of the propano bridge proves the absence of a syn-syn interconversion which would exchange $H_{A}$ and $\mathrm{H}_{\mathrm{B}}$ of each $\mathrm{CH}_{2}$ group. Thus, and in contrast to anti-5, syn-6 is a rather rigid molecule. Only the central methylene group very likely exhibits a "wobbling" motion of the trimethylene bridge ${ }^{[6 \mathrm{~d}]}$. This wobbling alters the environment of the individual $\mathrm{H}_{\mathrm{A}}$ and $\mathrm{H}_{\mathrm{B}}$, but does not eliminate the differences between these protons. No changes are observed for the signal pattern of the ${ }^{1} \mathrm{H}-\mathrm{NMR}$ spectrum of 6 measured in $\left[\mathrm{D}_{2}\right]$ tetrachloroethane between -80 and $100^{\circ} \mathrm{C}$, showing a remarkable conformational stability of this metacyclophane.

Usually, [3.2]metacyclophanes preferably adopt a syn conformation only if an intra-annular substituent is present ${ }^{[4-6]}$. However, in the case of the metacyclophane 6 the syn conformation is induced by substituents at the etheno bridge. To our knowledge this "conformational design" ${ }^{\left[{ }^{8]}\right.}$ of a metacyclophane by substituents has not been observed before, and this new methyl substituent effect on the preferred conformation and the different molecular flexibility of 5 and 6 can be attributed to the Van der Waals repulsion between the four methyl groups in 6 . In the anti conformation of [n.2]metacyclophan-10-enes the twisted etheno bridge tends to flatten the stair case structure to release the local strain. However, this flattening is especially opposed by the four methyl groups in the extra-annular positions 7 and 13 and in the bridge position 10 and 11 of 6 . This effect is absent in the syn conformations and, as a consequence, 6 favors this conformation.

The financial support by the Fonds der Chemischen Industrie is gratefully acknowledged. We thank Mrs. A. Mülverstedt, Universität Bielefeld, for her skilled technical support during the preparative work.

\section{Experimental}

Melting points, uncorrected: Electrothermal melting points apparatus. - IR: Perkin Elmer infrared spectrophotometer 377 and 883. - ${ }^{1}$ H-NMR: Bruker AM 300; TMS as internal standard. MS: Finnigan MAT $311 \mathrm{~A}$, direct insertion probe at suitable temperatures, $70 \mathrm{eV}$; high-resolution mass determinations with the same instrument at mass resolution $m / \Delta m=8000$. - Column chromatography and flash chromatography: Merck silica gel 60 (70-230 mesh/0.063-0.2 mm) - C/H analyses: Elementar-analytisches Laboratorium der Fakultät für Chemie, Universität Bielefeld.

Dimethyl 3,3'-(1,3-Propanediyl)bis(6-methylbenzoate) (2): A solution of $9.50 \mathrm{~g}(75 \mathrm{mmol})$ of oxalyl chloride in $25 \mathrm{ml}$ of dry di- 
chloromethane was added dropwise at $-20^{\circ} \mathrm{C}$ to a stirred suspension of $10.0 \mathrm{~g}(75.0 \mathrm{mmol})$ of anhydrous $\mathrm{AlCl}_{3}$ in $100 \mathrm{ml}$ of dry dichloromethane. After stirring for further $30 \mathrm{~min}$ at this temp., a

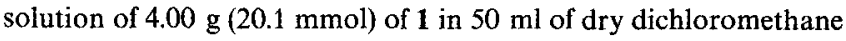
was added within $30 \mathrm{~min}$ at $-10^{\circ} \mathrm{C}$. The reaction mixture was stirred at $-10^{\circ} \mathrm{C}$ for $5 \mathrm{~h}$ and eventually poured onto $500 \mathrm{~g}$ of ice. The organic phase was separated, and the aqueous phase was extracted three times with $100 \mathrm{ml}$ of diethyl ether/dichloromethane $(1: 1)$. The combined organic phases were dried with $\mathrm{Na}_{2} \mathrm{SO}$. After evaporation of the solvents the residue was redissolved in $100 \mathrm{ml}$ of dry chlorobenzene and the solution refluxed for $5 \mathrm{~h}$ to achieve decarbonylation. After evaporation of the chlorobenzene under reduced pressure, the raw 1,3-bis[3-(chlorocarbonyl)-4-methylphenyl]propane was dissolved in $100 \mathrm{ml}$ of anhydrous methanol, this solution was refluxed for $6 \mathrm{~h}$, and the methanol was removed under reduced pressure. The residue was purified by flash chromatography (ethyl acetate). The pale yellow oil obtained was used without further purification. Yield of $23.96 \mathrm{~g}(58 \%)$. $-{ }^{1} \mathrm{H}$ NMR: see text. MS, $m / z(\%): 340(10)\left[\mathrm{M}^{+} \cdot\right], 308(100), 276(12), 249(8), 248(10)$, $177(8), 163(9), 145(67), 132$ (28), $131(25), 117(14), 105(36), 103$ (17), 91 (11), 77 (9), 59 (7).

3,3'-(1,3-Propanediyl)bis (6-methylbenzaldehyde) (3): $3.40 \mathrm{~g}(10.0$ mmol) of crude 2 in $100 \mathrm{ml}$ of dry THF was slowly added at room temp. to a suspension of $3.00 \mathrm{~g} \mathrm{(78} \mathrm{mmol)} \mathrm{of} \mathrm{LiAlH}_{4}$ in $100 \mathrm{ml}$ of dry THF. The mixture was refluxed for $12 \mathrm{~h}$. After cooling it was hydrolyzed, acidified with dilute $\mathrm{HCl}$, and the organic phase was separated. The aqueous phase was thoroughly extracted several times with dichloromethane. The combined organic extracts were dried with $\mathrm{Na}_{2} \mathrm{SO}_{4}$, the solvent was evaporated, and the raw 3,3'(1,3-propanediyl)bis(6-methylbenzenemethanol) ( $2.85 \mathrm{~g}$ ) was redissolved in $50 \mathrm{ml}$ of dry dichloromethane. The solution obtained was treated with $50 \mathrm{~g}$ of pyridinium chlorochromate $/ \mathrm{Al}_{2} \mathrm{O}_{3}(1 \mathrm{~g}=1$ mmol PCC) at room temp. for $3 \mathrm{~h}$. The reaction mixture was filtered and the residue washed extensively with dichloromethane. The combined filtrates were dried with $\mathrm{Na}_{2} \mathrm{SO}_{4}$ and evaporated under reduced pressure. The residue was purified by column chromatography giving a waxy material of 3 . The bis-aldehyde 3 proved to be very sensitive to oxidation by exposure to air and was used without further manipulations. Yield $1.42 \mathrm{~g}(50.5 \%)$. - MS, $m / z$ $(\%): 280(39)\left[\mathrm{M}^{+\cdot}\right], 265(3), 262(7), 237(3), 233(4), 160(17), 147$ (40), 134 (100), 133 (41), $132(8), 119(18), 117(17), 115(10), 106(40)$, 105 (62), 103 (19), 91 (40), 79 (24), 77 (33).

1,1'-(1,3-Propanediyl)bis(3-acetyl-4-methylbenzene) (4): $8.56 \mathrm{ml}$ $(9.42 \mathrm{~g}, 120 \mathrm{mmol})$ of acetyl chloride was slowly added at $-10^{\circ} \mathrm{C}$ to a suspension of $15.95 \mathrm{~g}(120 \mathrm{mmol})$ of $\mathrm{AlCl}_{3}$ in $160 \mathrm{ml}$ of dry chloroform. To this stirred mixture a solution of $3.14 \mathrm{~g}(14 \mathrm{mmol})$ of 1 in $100 \mathrm{ml}$ of dry chloroform was added dropwise at $0^{\circ} \mathrm{C}$. After the addition was complete, the mixture was allowed to reach room temp. and subsequently stirred for $30 \mathrm{~h}$. It was then poured on $400 \mathrm{~g}$ of ice, the organic phase was separated and the aqueous phase extracted with chloroform. The combined organic phases were dried with $\mathrm{Na}_{2} \mathrm{SO}_{4}$, and the solvent was evaporated. The residue was recrystallized from ethanol with the addition of a small amount of acetone. Yield of $42.02 \mathrm{~g}(47 \%)$, m.p. $62^{\circ} \mathrm{C}$. - IR $(\mathrm{KBr}): \tilde{v}=2920$ $\mathrm{cm}^{-1}, 2850(\mathrm{C}-\mathrm{H}), 1665(\mathrm{C}=\mathrm{O}), 1550\left(\mathrm{C}-\mathrm{C}_{\mathrm{arom}}\right), 1480,1435,1345$, $1285,1250,1175,940,810 .-{ }^{1} \mathrm{H}$ NMR $\left(\mathrm{CD}_{3} \mathrm{Cl}\right): \delta=1.95(\mathrm{~m}, 2 \mathrm{H}$, $\left.\mathrm{CH}_{2} \mathrm{CH}_{2} \mathrm{CH}_{2}\right), 2.48\left(\mathrm{~s}, 6 \mathrm{H}, \mathrm{CH}_{3}\right), 2.58\left(\mathrm{~s}, 6 \mathrm{H}, \mathrm{CH}_{3}\right), 2.68(\mathrm{t}, 4 \mathrm{H}$, $\left.\mathrm{CH}_{2} \mathrm{CH}_{2} \mathrm{CH}_{2}\right), 7.18(\mathrm{AB}, 4 \mathrm{H}$, aromatic $\mathrm{H}), 7.48(\mathrm{~s}, 2 \mathrm{H}$, aromatic $\mathrm{H})$.
- MS, $m / z(\%): 308(42)\left[\mathrm{M}^{+\cdot}\right], 293(45), 265(7), 161(29), 148(26)$, 147 (17), 133 (26), $117(8), 105$ (32), 91 (11), 43 (100).

$\begin{array}{lll}\mathrm{C}_{21} \mathrm{H}_{24} \mathrm{O}_{2} \text { (308.4) } & & \\ \text { Calcd. C 81.78 } & \text { H } 7.84 & \text { Mol. mass } 308.1776 \\ \text { Found C } 80.9 & \text { H } 7.93 & \text { Mol. mass } 308.1744\end{array}$

7,13-Dimethyl- and 7,10,11,13-Tetramethyl 3.2Jmetacyclophan10-ene (5 and 6). - General Procedure: The McMurry reagent was prepared from $23.8 \mathrm{~g}$ (125 mmol) of $\mathrm{TiCl}_{4}$ and $18 \mathrm{~g}(275 \mathrm{mmol})$ of $\mathrm{Zn}$ powder in $500 \mathrm{ml}$ of dry THF, carefully excluding air by a stream of purified $\mathrm{N}_{2}$. A solution of $3 \mathrm{mmol}$ of 1,3-bis(3-acyl-4-methylphenyl)propane ( $840 \mathrm{mg}$ of $3,925 \mathrm{mg}$ of 4) in $100 \mathrm{ml}$ of dry THF was added within $60 \mathrm{~h}$ to the black mixture of the McMurry reagent by using a high-dilution technique with continuous refluxing and stirring. The reaction mixture was refluxed for additional $8 \mathrm{~h}$, cooled to room temp., and hydrolyzed with $200 \mathrm{ml}$ of a $10 \% \mathrm{~K}_{2} \mathrm{CO}_{3}$ solution at $0^{\circ} \mathrm{C}$. The mixture was extracted extensively with dichloromethane, filtered, and the residue washed with dichloromethane. The combined dichloromethane extracts were dried with $\mathrm{Na}_{2} \mathrm{SO}_{4}$ and concentrated. The residue was purified by chromatography or recrystallized from ethanol.

5: Yiëld $135 \mathrm{mg}(18 \%)$, colorless oil. - ${ }^{1} \mathrm{H}$ NMR $\left(\mathrm{CDCl}_{3}\right)$ : see text. - MS, $m / z(\%): 248(100)\left[\mathrm{M}^{+\cdot}\right], 233(94), 219(47), 205(52)$, 203 (24), 191 (10), 190 (12), 189 (17), 128 (9), 119 (20), 91 (9).

$$
\begin{array}{lll}
\mathrm{C}_{19} \mathrm{H}_{20}(248.4) & & \\
\text { Calcd. C 91.88 H 8.12 } & \text { Mol. mass 248.1565 } \\
\text { Found C } 92.0 & \text { H } 8.00 & \text { Mol. mass 248.1571 }
\end{array}
$$

6: Yield $220 \mathrm{mg}(26.5 \%)$, m.p. $158^{\circ} \mathrm{C} .-\mathrm{IR}(\mathrm{KBr}): \tilde{v}=3010 \mathrm{~cm}^{-1}$, 2930, $2860(\mathrm{C}-\mathrm{H}), 1605,1560\left(\mathrm{C}=\mathrm{C}, \mathrm{C}-\mathrm{C}_{\text {arom }}\right), 1495,1435,1380$, 910, 810. - ${ }^{1} \mathrm{H}$ NMR $\left(\mathrm{CDCl}_{3}\right)$ : see text. - MS, $m / z(\%): 276(89)$ $\left[\mathrm{M}^{+\cdot}\right], 261(100), 246(32), 233(30), 217(21), 203(10), 155(10), 143$ (15), 141 (13), 128 (18), 115 (12), 105 (10), 91 (11), 57 (21).

$$
\begin{array}{lll}
\mathrm{C}_{21} \mathrm{H}_{24}(276.4) & & \\
\text { Calcd. C 91.25 H } 8.75 & \text { Mol. mass 276.1878 } \\
\text { Found C } 90.3 & \text { H } 8.94 & \text { Mol. mass 276.1876 }
\end{array}
$$

${ }^{11}$ H.-F. Grützmacher, E. Neumann, F. Ebmeyer, K. Albrecht, P. Schelenz, Chem. Ber. 1989, 122, $2291-2297$.

[2] J. E. McMurry, M. P. Flemming, K. L. Kees, L. R. Krepski, J. Org. Chem. 1978, 43, 3255-3266.

${ }^{[3]}$ F. Ebmeyer, Diplomarbeit, Universität Bielefeld, 1986.

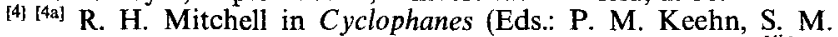
Rosenfeld), Academic Press, New York, 1983, vol. 1. - ${ }^{[4 b]}$ R. H. Mitchell, T. K. Vinold, G. W. Bushnell, J. Am. Chem. Soc. 1985, 107, 3340-3341. - ${ }^{[4 c] ~ F . ~ V o ̈ g t l e, ~ C y c l o p h a n-C h e m i e, ~}$ Teubner, Stuttgart, 1990. - [4d] J. Breitenbach, R. Hoss, M. Nieger, K. Rissanen, F. Vögtle, Chem. Ber. 1992, 125, 255-258. ${ }^{[5]}$ D. Krois, H. Lehner, Tetrahedron 1982, 38, 3319-3324.

[6] [ba] H. Förster, F. Vögtle, Angew. Chem. 1977, 89, 443-455; Angew. Chem. Int. Ed. Engl. 1977, 16, 429-440. - ${ }^{\left[{ }^{6 b]} \mathrm{R}\right.} \mathrm{R}$. H. Mitchell, K. S. Weerawana, G. W. Bushnell, Tetrahedron Lett. 1984, 25, 907-910. - ${ }^{[60]}$ K. Böckman, F. Vögtle, Chem. Ber. 1981, 114, 1065-1073. - ${ }^{[6 \mathrm{dc}} \mathrm{M}$ M. F. Semmelhack, J. J. Harrisson, D. C. Young, Y. Guitierrez, S. Rafii, J. Clardy, J. Am. Chem. Soc. 1985, 107, 7508-7514. - ${ }^{[6 e]}$ For a recent example see T. Yamato, J.-i. Matsumoto, K. Tokuhisa, M. Kajihara, K. Suehiro, M. Tashiro, Chem. Ber. 1992, 125, 2443-2454.

[7] [7a] H. Blaschke, C. E. Ramey, I. Caldes, V. Boekleheide, J. Am. Chem. Soc. 1970, 92, 3675-3679. - ${ }^{[76]}$ H.-F. Grützmacher, W. Husemann, Tetrahedron Lett. 1985, 26, 2431-2434. $-{ }^{{ }^{7 \mathrm{cl}} \mathrm{R}} \mathbf{R}$. H. Mitchell, G. J. Bodwell, T. K.Vinod, K. S. Weeerawana, Tetrahedron Lett. 1988, 29, 3287-3290.

${ }^{[8]}$ R. W. Hoffmann, Angew. Chem. 1992, 104, 1147-1157; Angew. Chem. Int. Ed. Engl. 1992, 31, 1124-1134.

[460/92] 